Usage, Usability, and Utility of 3D City Models, 02003 (2012)

DOI: $10.1051 / 3 \mathrm{u} 3 \mathrm{~d} / 201202003$

(c) Owned by the authors, published by EDP Sciences, 2012

\title{
Extending 3D city models with legal information
}

\author{
A.U. Frank, T. Fuhrmann and G. Navratil \\ Institute of Geo-information, Vienna University of Technology, Vienna, Austria
}

\begin{abstract}
D city models represent existing physical objects and their topological and functional relations. In everyday life the rights and responsibilities connected to these objects, primarily legally defined rights and obligations but also other socially and culturally established rights, are of importance. The rights and obligations are defined in various laws and it is often difficult to identify the rules applicable for a certain case. The existing $2 \mathrm{D}$ cadastres show civil law rights and obligations and plans to extend them to provide information about public law restrictions for land use are in several countries under way. It is tempting to design extensions to the $3 \mathrm{D}$ city models to provide information about legal rights in $3 \mathrm{D}$. The paper analyses the different types of information that are needed to reduce conflicts and to facilitate decisions about land use. We identify the role 3D city models augmented with planning information in 3D can play, but do not advocate a general conversion from 2D to 3D for the legal cadastre. Space is not anisotropic and the up/down dimension is practically very different from the two dimensional plane - this difference must be respected when designing spatial information systems. The conclusions are: (1) continue the current regime for ownership of apartments, which is not ownership of a 3D volume, but co-ownership of a building with exclusive use of some rooms; such exclusive use rights could be shown in a 3D city model; (2) ownership of 3D volumes for complex and unusual building situations can be reported in a 3D city model, but are not required everywhere; (3) indicate restrictions for land use and building in 3D city models, with links to the legal sources.
\end{abstract}

\section{INTRODUCTION}

Several cities around the globe have produced 3D city models and more are undertaking to build such models. Such models have various uses, for example the city of Vienna uses its 3D city model in decision processes for planning building projects and zoning [1]. Existing 3D city models represent the physically existing objects in space, primarily the surface of the earth, with buildings and larger plants, e.g. trees, on it. Occasionally, physical objects in the underground are represented to facilitate planning of underground facilities but also to discuss evacuation plans for underground rails [2]. The representations are of different Levels of Detail 3, 4; more detail often includes not only information about the geometric aspects of the 3D objects, but also function and classification of use. The current 3D city models are focused, ontologically speaking, on the "Physical reality" (tier two) of a tiered ontology [5].

Social interaction imposes a second structure, called "socially constructed objects" on the world [6]. Most relevant, and the focus of this paper, are the legal constructions, which produce rights and obligations governing the behaviour of everybody and which are, if needed enforced by the government. This is especially ownership of land, but equally important are the restrictions on the ownership resulting from governmental decisions. Other social constructions, some less binding than legal constructions, are equally present and should be considered in 3D city models. The legal constructions of ownership in 2D have the longest pedigree and provide guidelines for the construction of 3D social objects and a possible 3D cadastre [7-10].

This is an Open Access article distributed under the terms of the Creative Commons Attribution License 2.0, which permits unrestricted use, distribution, and reproduction in any medium, provided the original work is properly cited. 
The paper focuses on the extension of legal regulations for space from $2 \mathrm{D}$ to $3 \mathrm{D}$. It first reviews the different types of legal regimes for space and how they affect spatial decisions; the focus is on private ownership and public urban planning restrictions. The section 3 discusses the demarcation of socially constructed objects, e.g. parcels, to count the delimited physical object as an object of rights and obligations; this constructs the connection between the physical and the legal realm and points to the difficulty of fixing geometric extend precisely in space. Section 4 explains why real estate ownership and other rights in land must be publicly registered. In section 5 issues of maintenance, which are different for legal and other socially constructed objects compared with the physical 3D city model, are addressed. Section 6 uses the established framework to ask the question what information is required? When? And with what legal force? The section concludes then with recommendations for a legal 3D cadastre, but stops short of a general recommendation to make all cadastral units 3D. Section 7 extends the results from the legal realm to the general realm of social constructions. The conclusion section summarizes the results and formulates some advice for the construction of 3D city models which merge physical and social information.

\section{LEGAL INFORMATION ON SPACE}

Human coexistence requires rules to reduce conflicts and facilitate efficient and conflict free interaction. Human history has developed rules and methods for the enforcement of rules, which assign rights and obligations to the participants in an interaction. The major concept is a "right" of an actor to do something and the "obligation" of an actor, not to do some actions - usually to tolerate the actions of another. "Ownership" of a thing is the fundamental relation between a person and an object, the person having all rights which are related to an object; ownership of land is a special form of ownership and gives complete control over a piece of land, within the restrictions of the legal context of a jurisdiction. Other rights, e.g. security rights for mortgages, rights-of-way, can be granted by the owner to others.

Following the doctrine of separation of powers of Tocqueville, the legislator produces laws, which control an undetermined number of not yet occurred cases in specific processes. The legislator can delegate in a law some rule making power to other public agencies, for example rules on taxation, waste disposal, nature conservation, urban planning etc. Rules apply to all people in a jurisdiction.

Civil law regulates the relations between actors, i.e. natural and legal persons. The partners in a contract are on equal standing. Examples for civil law regulations are the rules for sales, renting of apartments and marriage. Public and administrative law gives rules for the interaction between the state and the private persons; special safeguards apply because the partners involved in a contract are not on equal standing. Examples for public law are rules about taxation, environmental pollution or urban planning. The third major type of laws, namely criminal law forbidding theft, murder etc. is not relevant in the present context.

Both private and public law is relevant for our dealings with parcels and other legal spatial objects.

\subsection{Private law regulations}

The principal figure is ownership, which is the complete control of a person over a thing and which has to be respected by all others. Important is to consider, how others are informed about a person's ownership of a thing. Ownership rights of things are typically publicized by physical possession - if I have a thing physically in my hand all others can assume that I own it (unless they know that I am only a lender and the owner is another).

Publication of ownership by possession does not work for land and other immobile things. Ownership of land is publicized by registration - the original enacted physical taking of possession is not efficient [11]. Public registries serve this function: everybody can get information about who owns a piece of land from a publicly held land register. 
Public registers record the ownership of land (title to land, right to land) and give authoritative information about it. In Austria and many other countries, private law restrictions on the use of land are stored in specific institutions, typically called land registers. These institutions specify the rights that connect persons (subjects) with objects, i.e. land [12]. In a continental land registry system, the registered owner is the owner without any further proof and in many systems, rights (e.g. mortgages) which are not recorded cannot be enforced to a buyer in good faith. A potential buyer can conclude from the absence of information that such rights do not exist (an application of the Closed World Assumption in law [13]).

The land registry (or title registry) has the purpose to provide authoritative, reliable information about civil law rights and obligations associated to a parcel, so that others can assess the value. A potential buyer or a bank considering granting a mortgage needs to know not only the size of the parcel (2D or 3D) but also rights others have regarding the parcel (mortgages, liens and easements). In systems with a "numerus clausus" only a small number of types of rights can be registered and enforced against third parties; the limited number of rights reduces the potential for errors in the system and increases the reliability of the information obtained from them.

Today only a small part of the information influencing the value of a parcel comes from civil law rights and obligations. Over the past years, public law restrictions have dramatically increased - consider urban planning rules - and this information is not in the title registry, because these are restrictions on the rights coming from public law.

\subsection{Public law regulations to land ownership}

Public law regulations are specified in various locations and it is usually difficult to establish a complete list of all the restrictions applicable to a parcel. There are numerous special laws, from which restrictions on the use of land can follow, e.g. environmental laws, protection of natural or cultural heritage, mineral rights, and transportation. The laws can be enacted by different levels of government (state, province, and town). In Austria we suffer from an enormous number of new or changed laws every year. Access is by keywords, level of government, but not by spatial criteria. It would be most useful to find the regulations affecting a parcel by location.

\subsection{Urban planning}

Governments at different levels are involved in planning. In Austria and most European countries, local urban planning determines the use of land, in particular, what can be built on a parcel and how big the buildings may be. This is typically limited in size and location, but also in height and thus a prime candidate for presentation in a $3 \mathrm{D}$ city model.

\subsection{Conclusions}

The private law registries register rights and obligations of privates which are fixed in space. The boundaries of one parcel (one volume) are always also the limits of another person's parcel or volume. Therefore the determination of boundaries is an important and permanent concern.

The public law creates nearly always restrictions for all privates for certain actions, especially the construction of buildings. Such restrictions are spatially fixed as $2 \mathrm{D}$ areas or $3 \mathrm{D}$ volumes. The boundaries must be determined only when a private plans an action which could be restricted, primarily building construction. 


\section{DELIMITING THE OBJECT OF LEGAL RIGHTS}

If a right or an obligation exists, the next question in real estate law is the determination of the object of the rights, which means the determination of its boundaries. A parcel needs delimitation - typically by boundary markers and measurements in case the markers are lost. Today, with more precise and faster measurement methods than 50 years before, markers are not always set and the boundaries are only determined by coordinate values; in case of conflict, the location of the boundary must be set out in the physical world by a surveyor.

Ordinary two dimensional parcels extend from "hell to heaven" (ad caelum et ad inferos), today restricted to what is technically usable; it does not need a precise limitation in height. A 3D volume which is subject to special rights and obligations will need a boundary and the boundary needs markers for its boundary points or coordinates for them. For the connection of the 3D city model with the legal objects, the spatial extent of legal objects needs to be defined in the same reference system as the remainder of the 3D city model. For a 3D cadastre, a volume needs height limitations and these call for a height reference frame, which is even more problematic than the 2D position of boundary markers. Local movements of the surface or of buildings occur often and precise height measurements are more difficult than 2D positions. GPS, for example, gives height coordinates only 2-4 times less precise than 2D coordinates, and only with respect to local benchmarks.

\subsection{Private law: Parcel boundaries}

For the 2D parcels, the land register in Austria, for example, refers to the cadastre for spatial reference. The cadastre - maintained by a public agency in Austria - then shows a boundary for the area affected by the right. In a traditional cadastre the boundaries are marked and if markers are lost, the boundary points are reconstructed with measurement from other local markers. Modern surveying practice, e.g. GPS, seems to enable a cadastre simply based on coordinates without markers in the terrain. This practise is based on the assumption that land and buildings are stable, which is, however, a gross simplification; with today's measurement methods, continental plate tectonics movements with speeds in the order of centimetres per year are detectable, local movements (land slides) are noticed when GPS measurements change, and local deviations caused by errors and imprecision in old measurements in the range of metres, compared to a standard solution like the European Terrestrial Reference Frame, are common [14]. A comparison of the current map data with the results of the original surveys indicates often deviations in the range of metres [15]. The concept of reconstructing a boundary marker at "exactly the same location" is doubtful.

In European cities, many apartments are owned individually; this seems to be a case of owning a 3D volume - the apartment - and thus seems to call for a 3D legal cadastre. This is currently not the case; what appears as an ownership of an apartment is legally constructed as a co-ownership of an ideal part of the building with the exclusive use right for an apartment within its walls. This construction avoids the need for a 3D description of the apartment - markings on a 2D floor plan are sufficient, and thus avoids the problem with height determination. The apartment is delimited by broad boundaries, realized as walls, not fixed by 3D coordinates. The problems with 3D reference systems are completely avoided. Reference systems for height measurements are more difficult than the reference systems for $2 \mathrm{D}$, and height measurements are more difficult and less precise than measurements of 2D positions. The construction of co-ownership resolves also the issues of maintenance of the building, access across halfway and for pipes etc.

\subsection{Public law: Limits of restrictions}

The situation is more complicated for the public law restrictions, because the limits of restrictions are described in laws and regulations in the abstract, whereas in planning documents they are spatially fixed. 
The application of descriptions in laws and regulations, which create restrictions to a specific area, needs a legal interpretation of the situation and subsumption under the rule of law. For example, a law may state limitations to building in forest areas. To apply the rule, one has first to identify whether an area is forest or not. It seems possible to code some of such regulations in computer procedures which indicate spatially where restrictions may apply (note: such procedures can only give indications, where and where not rules apply; a final determination is by legal procedures and eventually by a court).

Restrictions from public law are often affecting volumes and a 3D registry of public law restrictions would be most welcome. Examples are restrictions on how much shadow a building may cast on a neighbour, restrictions in how high buildings may be above the ground etc. It would be highly beneficial, if such localized restrictions on use of land - e.g. construction of buildings - could be communicated in a 3D cadastre, together with the 3D city model showing existing buildings and it is technically feasible, to show planned buildings in the same scene. This would allow to visually control, where a planned building extends beyond the boundaries of permitted volume and would likely lead to better arrangements of new buildings.

Restrictions resulting from urban planning documents are spatially referenced and can be integrated with 3D city models, provided the difficulties with differences in the reference systems can be overcome. The boundaries of urban planning measures are not typically congruent with parcel boundaries and difficulties with the applicability of a measurement which covers only part of a parcel may occur; again, such questions must be dealt with when a private plans an activity.

\section{MAINTENANCE OF THE SYSTEM}

Building information systems is relatively easy compared with the long term maintenance of them. A legal cadastre is a continuous recording of all changes occurring; the current situation is the result of the continuous chain of transfer of ownership and other rights between privates - independent of the specifics of the registration system (i.e. a continental European registry in the tradition of code Napoleon, or a common law registry of deeds). Unlike a data collection regarding physical objects which can be redone at regular intervals by systematic data collection activities - e.g. the construction of a 3D city model from LIDAR data - a legal cadastre is very costly to establish from scratch; it is typically 10 to 1000 times more expensive to collect the state of legal rights of parcels than to collect the boundary of the parcel [16]. Physical boundaries are usually immediately visible, legal rights must be collected from the documents and memories of the people who created them.

\section{WHAT CAN A LEGAL CADASTRE PROVIDE?}

The analysis of the legal situation and a consideration of the needs of the public lead to some indications what a legal 3D cadastre could do.

The public needs a place to get authoritative and reliable information about rights and obligations regarding actions in space: where is the place (i.e. what are the boundaries)? What is permitted to do at a place?

Ownership and the rights to regular use of a space are limited by the right of my neighbours; thus the demarcation of boundaries is important and boundaries must be permanently visible to avoid conflicts. This means boundaries must be marked physically and backed up by measurements.

The right to construction (and similar rights to make major changes) is seldom used and limited by public law, urban planning etc. Information about restrictions is most important and influences the value of land enormously, but a final determination outside of court procedures is not always possible. A cadastre of public law restrictions can only be indicative, but not definite. 
From this review of the needs and the desire to allow ownership not only for 2D pieces of land, but also ownership structured in 3D, follows:

(1) ownership of apartments and office space in buildings is, in reality, ownership of a 3D volume, but legally not constructed as such. The current legal regime of co-ownership of the building and the exclusive use rights for an apartment in the building is more suitable than a naked ownership of a 3D volume. It deals properly with rules for the maintenance of the building. No difficult measurement questions arise, as the boundaries of the apartments are realized as walls, doors and windows. To show, as indication, the placement of private exclusive use rights in a 3D city model may be useful, but should not have legal standing;

(2) there exist few cases, usually when establishing rights to build on the ground of others, where rights should be delimited as 3D volumes [17]. Ownership or other rights of 3D volumes for complex building situations (e.g. constructions above public transportation and the required rights of way) are seldom and require complex legal arrangements, due to the complexity of the requirements for physical support and access. They are possible with the current Austrian legal system and need 3D measurements for their definition; it is recommended that height references are referenced to nearby physical benchmarks, not in an absolute reference system. The current neighbour rights (e.g. the right and obligation to allow the natural surface flow of water, rights of way assigned if no other access is possible etc.) can be applied;

(3) to make public restrictions, primarily urban planning regimes, visible in a 3D city model is possible and it is not a substantial increase in difficulty to construct a 3D information system for public law restrictions on space, which is currently under way in several countries.

In summary: a private law cadastre for 3D seems not warranted, but indications of quasi private ownership of parts of buildings as a form of making visible the exclusive use rights of co-owners can be useful. A registry of public law restrictions on land use is urgently needed to help citizens to identify the restrictions possibly applying to land; such registries are currently planned or realized in several countries and they should, from the beginning, be designed for 3D and for integration with $3 \mathrm{D}$ city models.

\section{PLACES - OTHER SOCIALLY CONSTRUCTED OBJECTS}

Society may assign meanings to objects, following Searle's construction of "X counts as Y in context Z", in other contexts than legal. For example, a physical location (e.g. a field) may have been the location of a battle and thus acquire special (social) meaning for a community (i.e. a context Z), but not for another. Conflicts occur when another group which has another context and for which the place has no meaning plans to change something, not respecting the meaning the first group assigns to it. Examples abound, e.g. the Kosovo Polje (for Serbs), different parts of Jerusalem (for different religious groups), and lead unfortunately often to serious conflicts. Assignment of meaning is - as legal assignments - usually in 2D and uses a concept comparable to the legal definition of extension of ownership, but also rooms, i.e. $3 \mathrm{D}$ volumes with special meaning exist. For example, a room in which Hitler was received in the Volkstheater Wien, is protected, the balcony from which the signing of the Austrian peace contract after WW II was proclaimed is another 3D situation, which has special meaning for Austrians (see figure below).

In general, the reasons for legal 3D cadastre and the problems related to it give valid guidelines for other socially constructed 3D objects and their representation in future 3D city models.

\section{CONCLUSIONS}

The 3D city models report primarily the physical (volume) description of buildings and other permanent features in a cityscape. The restriction to physical objects is limiting, because human activities are 


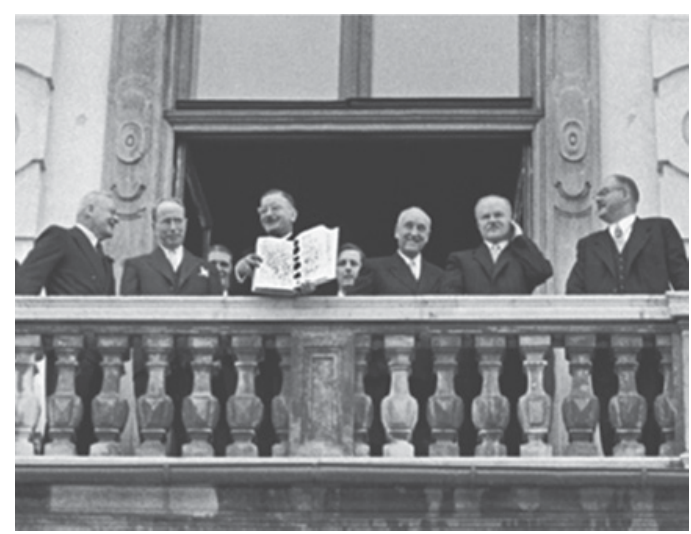

Figure 1. The balcony where the Austrian foreign minister Leopold Figl showed the signed state treaty (source: uibk.ac.at).

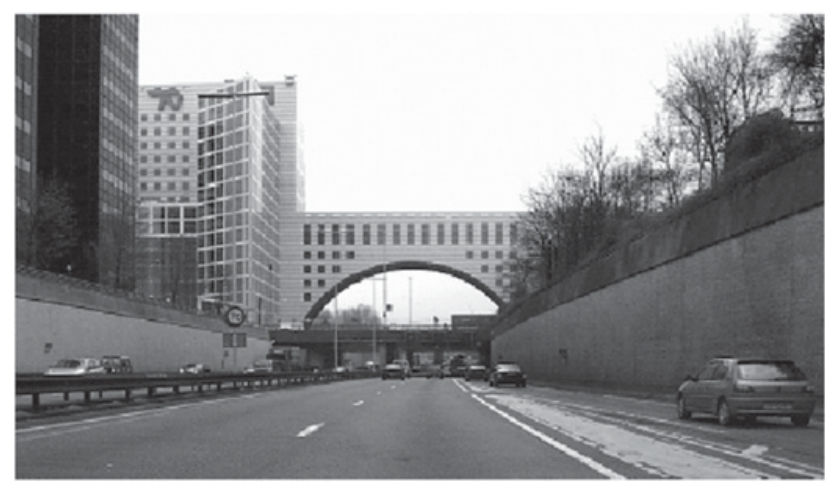

Figure 2. Building above a motorway in Den Haag [18].

mostly guided by social constructions: we go to Church (not just a building), university (also not just the building, but the institution). Very important and well studied are legal constructions: pieces of lands are legal parcels, and as such owned by specific persons. Others have to respect this ownership. Public bodies produce regulations for the use of space, restricting access, building construction etc.

Including the legal information in a 3D cadastre seems useful. Geometrically, it requires that the spatial reference system used by the legal cadastre is compatible with the spatial reference system of the 3D city model. The general rule, that a building is owned by the owner of the ground, gives ownership of most buildings immediately from the registered parcel ownership. A general extension of the legal cadastre to 3D seems not warranted. In few, exceptional cases, e.g. when constructing above a public right of way, rights should be described as a 3D volume with boundaries, but in the general case of "ownership of apartments" in cities, the current construction as co-ownership of the building with exclusive use rights for the apartment is more appropriate, as it organizes also the interactions between the owners for building maintenance, common services, access etc. (see figure below).

The ever increasing importance of public law restrictions on the use of land are mostly relevant when constructing or renovating a building. It would be helpful, if a cadastre of public rules regarding land would exist and some countries are about to build some. Several restrictions limit height of buildings or building in certain parts of a parcel and thus visualizations as 3D volumes would be very helpful. The complexity of the rules, however, suggests that only an indication of what is or is not permitted is 
Usage, Usability, and Utility of 3D City Models

possible and no authoritative answer can be given automatically; a determination in a particular case remains to the administrative authorities with a possibility to check its decisions in a court of law.

\section{References}

[1] Dorffner, L. and Zöchling, A. (2003). Das 3D modell von Wien - Erzeugung und Fortführung auf Basis der Wiener Mehrzweckkarte. Proceedings of the CORP 2003, Vienna: CORP-Competence Center of Urban and Regional Planning, pp. 161-166.

[2] Forkert, G. (2006) Modellierung und Verwaltung von U-Bahnanlagen im Rahmen des digitalen 3D Stadtmodells, in M. Schrenk (Ed.), Proceedings of the CORP 2006 and Geomultimedia06, Vienna: CORP - Competence Center of Urban and Regional Planning, pp. 665-668.

[3] Döllner, J., Buchholz, H. (2005). Continuous level-of-detail modelling of buildings in 3D city models. Proceedings of the 13th annual ACM international workshop on Geographic information systems. ACM New York.

[4] Navratil, G., R. Bulbul \& A.U. Frank (2012). Maintainable City Models for Sustainable Development. Int. J. Sustainable Society, 5(2), pp. 97-113.

[5] Frank, A. (2001). Tiers of ontology and consistency constraints in geographical information systems. IJGIS (Volume 15, Issue 7).

[6] Searle, J. R. (1995). The construction of social reality. USA: Simon \& Schuster.

[7] Zevenbergen, J. 2002. Systems of land registration. Ph.D., Technical University, Delfts, Netherlands.

[8] Navratil, G. \& Hackl, M. (2007). 3D - Kataster. Proceedings of the CORP 2007, Vienna: CORPCompetence Center of Urban and Regional Planning.

[9] Döner, F., Thompson, R., Stoter, J., Lemmen, Ch., Ploeger, H., van Oosterom, P. \& Zlatanova, S. (2010). 4D cadastres: First analysis of legal, organizational, and technical impact - With a case study on utility networks. Land Use Policy, 27(4), pp. 1068-1081, Elsevier.

[10] Stoter, J., Salzmann, M. (2003). Towards a 3D cadastre: where do cadastral needs and technical possibilities meet? Elsevier, Computers environment and urban systems 27(4): 395-410.

[11] Sachsenspiegel (Landrecht) (1987). Reclam Universal-Bibliothek, Nr. 3355.

[12] Twaroch, C. \& Muggenhuber, G. (1997). Evolution of land registration and cadastre; Case study: Austria, Joint European conference on geographical information.

[13] Reiter, R. (1978). On closed world data bases. In H. Gallaire and J. Minker, editors, Logic and Data Bases, pp. 119-40. Plenum Publ. Co., New York.

[14] Höggerl, N. \& Imrek, E. (2007). Recent Steps towards the Introduction of ETRS89 in Austria. Geodetski Vestnik, Journal of the Association of Surveyors of Slovenia 51(4): 742-750.

[15] Navratil, G., Hafner, J. \& Jilin, D. (2010). Accuracy Determination for the Austrian Digital Cadastral Map (DKM). Proceedings of the 4th Croatian Congress on Cadastre with International Participation (Medak, D., Pribicevic, B. \& Delak, J., eds.), 15. - 17.2.2010, Zagreb, Croatia, pp. 171-181.

[16] Lambert, V., Frank, A. U., Cisneros, A., Sherrill, D., DeWalt, B., Abellan, A., \& Uquillas, J. (1990). Ecuador Land Titling Project Evaluation. Report, Bethesda, MD, DAI, December 1990.

[17] Stoter, J. \& Zevenbergen, J. (2001). Changes in the definition of property: a consideration for a 3D cadastral registration system. Proceedings FIG Working Week.

[18] Stoter, J. \& van Oosterom, P. (2006). 3D Cadastre in an international context. CRC Press, Taylor \& Francis, Boca Raton, NY, 323 p. 